\title{
La cultura tamazight: un tabú incomprensible
}

\author{
Rachid Ahmed Raha
}

\section{Resumen}

La década de los años ochenta se manifestó por el despertar de las culturas del Tercer Mundo y por la afirmación de las distintas identidades, de las minorias y de las nacionalidades tanto en Europa Occidental como en la Oriental. Y la identidad bereber que en su término autóctono se denominó Tamazight no tiene excepción: la cuestión Tamazight surge con demasiada elocuencia tanto en Francia como en el Magreb. La reconstrucción de dicha cultura no deja de suscitar indefinidas polémicas e irreductibles problemas.

Este artículo no es un estudio exhaustivo de la cuestión ni un ensayo puramente académico, sino simplemente una introducción de los grandes rasgos definidores de esta cultura, demasiado desconocida, a pesar de ser un notable patrimonio de la histórica ciudad de Melilla. De una forma general valoraremos los dominios antropológicos, geográficos, histórico, la evolución socio-económica y el campo lingüístico. Y todo esto partiendo de nuestra época.

\section{Introducción}

Una obvia advertencia a los lectores: precisar que este trabajo se inscribe en el ámbito cultural, fruto de un largo estudio del tema, 
con el único fin de dar una visión más cientifica de la cuestión Tamazight.

Como relató Claudio A. Barrio en su interesante artículo "En busca de la identidad bereber. Los seis ciclos históricos", publicado en el libro Las comunidades europeas, el Mediterráneo y el Norte de Africa, Melilla, 1989, Melilla siempre fue testimonio de la presencia bereber durante las épocas de su evolución histórica.

Nuestra primera observación, parte de la presencia en Melilla de una comunidad demográficamente significativa denominada por el término de "musulmana", que en 1986-1987 fue motivo de vivos y polémicos debates políticos. Melilla tomó conciencia de una comunidad demasiado desfavorecida económicamente. En ese sentido fueron tomadas medidas urgentes por las autoridades para mejorar sus condiciones económicas, tras solventar primeramente su situación documental. Aparte del factor económico, todavía dicha comunidad sigue mostrando una notable deficiencia cultural. Esta carencia cultural se observa fácilmente en los centros escolares, donde los altos índices de fracaso escolar, en general, se encuentran entre los niños musulmanes.

Esto no sólo en los centros escolares públicos melillenses, sujetos a un "ideario" netamente español, sino incluso en centros como la "Residencia de Estudiantes Marroquíes-Musulmanes", con un planteamiento educativo de "ideario" arabo-musulmán, donde el abandono escolar antes de cumplir la enseñanza básica es frecuente. Estos masivos fracasos y abandonos escolares tienen como origen la ignorancia y la marginación de su cultura. La cultura Tamazight está siempre ligada a la tradición, al folklore y, en resumidas cuentas a la religión islámica.

El hecho de asociar las comunidades a términos religiosos deja sobreentender una falta de permeabilidad y una cierta incompatibilidad de las dos mayoritarias comunidades que componen la población melillense. Como si ocurriera que cruzadas e inquisiciones, fanatismos y enemistades, inconveniencias e intolerancias fueran escenas diarias de la realidad melillense. Todo esto, por supuesto, dentro del plano inconsciente e ideológico, en general, de la persona. Cosa que no ocurre en la realidad, aunque hay que reconocer que existe una falta de comprensión mutua de los diferentes conjuntos culturales. En este artículo utilizare o definiré a la comunidad musulmana desde el punto de vista étnico.

Concluyo mi introducción con la siguiente cita de Marfa Angeles Antelo y Francisco Javier Núñez, realizada en el "Congreso Hispano Africano de las Culturas Mediterráneas", celebrado en Melilla 
en 1984: "Creemos que un mayor conocimiento del pueblo musulmán, su cultura, su religión, su historia, sus tradiciones, en suma su civilización, favorecerfan la integración entre ambos grupos sociales, así como la amplitud y profundidad de las relaciones entre ellos".

Como es sabido, la entidad bereber no se resume únicamente en el lenguaje hablado sino que reúne distintos criterios que la investigación científica nos está dando a conocer cada vez más donde se encuentra arraigada esta cultura.

\section{Antropología y repartición geográfica de los imazighen}

Cada vez que se habla de los bereberes, la primera pregunta que suele plantearse es la de sus misteriosos orfgenes. Y siempre suelen atribuirle orfgenes ajenos y existencia en épocas antiguas y preislámicas. No voy a detallar las numerosas teoŕas ni a relatar las distintas épocas paleolíticas y neolíticas, quisiera sólo añadir a este respecto, la interpretación de las pinturas rupestres descubiertas en la famosa región de Tassilin- Aijjer, al sur de Tamanrasset, en Argelia.

Estas muestras pictóricas reflejan un alto grado de desarrollo de la vida social de nuestros ancestros bereberes: aparte de pintar toros, vacas y caballos, dibujaron escenas pastoriles, escenas de caza colectiva con perros domesticados, escenas familiares con las mujeres cerca de las aldeas, y por último carros de combate con dos ruedas. Para no extenderme en este tema antropológico es preciso que comente de una manera objetiva un poco la última teorfa de la antropologfa moderna. Esta se basa en la distancia de Hiernaux que toma en consideración determinados factores que pueden ser reflejo de una distancia genética. Si el hombre de Mechta-el Arbi y de la cueva de Taforalt se ha revelado de origen autóctono; antropológicamente el ochenta por ciento - según Gabriel Camps- de la población magrebí actual pertenece al tipo mediterráneo, idéntico a los f́beros y a los italianos del Sur.

Aś, partiendo de los recientes estudios de antropología, basados en la distancia antropológica aplicada a los diferentes grupos sociales de los imazighen actuales tuvo concluyentes resultados. Por ejemplo, la comparación de los argelinos donde los bereberes no sobrepasan el treinta por ciento de la población, tuvo como resultado lo siguiente: un árabe de las llanuras occidentales u orientales tiene más parentesco con un kabiliano bereber que un mozabita, o uno natural de Chawia, todos ellos bereberes. 
Esto nos afirma que en Argelia la mayoría de los grupos sociales pertenecen a la etnia bereber. Los mismos resultados antropológicos fueron observados entre los marroquíes, y los libios. Todos estos estudios convergen en la conclusión general: en el Magreb, la mayoría de su población pertenece a la etnia bereber, donde el elemento árabe ha ejercido, a excepción de los tunecinos, poca influencia desde el punto de vista de la antropología física. Sólo existen bereberes: bereberófonos y bereberes arabofonos o arabizados. Los que se autodenominan árabes, sólo pueden ser considerados así desde el punto de vista cultural y lingǘrstico, identificándose con la unidad arabo-islámica. Como subraya Gabriel Camps "es una extraña historia la transformación etno-sociológica de una población de muchos millones de bereberes por unas docenas de miles de beduinos árabes".

Si la lengua tamazight se hablaba ya antes de la conquista árabe, desde Egipto occidental a Marruecos, y desde las costas mediterráneas del Norte de Africa hasta los contornos del Gran Sahara, en la actualidad se ha reducido enormemente a limitadas áreas geográficas más o menos densas, repartidas entre una docena de parses.

Marruecos, donde no existen datos demográficos de la 18 bereberofonía, es el país que cuenta con la mayoría de sujetos. Aún careciendo de estadisticas fiables podemos afirmar que de un cincuenta a sesenta por ciento de la población son bereberófonos, repartidos en tres grandes áreas geográficas: en las montañas del Rif donde se habla el Tarifit, en el Medio-Atlas y en una parte del Alto Atlas donde predomina el Tamazight, y, por último, en la parte Sur, el Alto Atlas, el Anti-Atlas, y la zona Sur que pertenecen al dominio Tashelhit.

En Argelia un treinta por ciento de la población es bereberófona y está concentrada en la pequeña y grande Kabilia, en Aurés y en Mzab. Los tuaregs ocupan el Sur sahariano en Ahagar y Aijjer. Estos últimos se hallan también en Níger, Mall, en Djebl Nefoussa de Libia y en Mauritania. Existen otros bereberofonos en Djerba de Tunicia, en Siwa, de Egipto, y, por último, testimonialmente, en las Islas Canarias donde los guanches no han desaparecido del todo, sin olvidar las colonias de inmigrantes de la Europa industrial.

\section{El papel histórico}

La historia junto a la lingüística, son los grandes pilares que 
definen la entidad bereber. Si las versiones oficiales siempre asignan un papel pasivo en el teatro de la historia de los bereberes, con las siguientes líneas vamos a intentar desenmascarar estos prejuicios y estas falsas afirmaciones de la "memoria del pueblo". No vamos a mencionar los capítulos referentes a los reyes bereberes en la época preislámica ni vamos a relatar la conquista de Al-Andalus por las tribus bereberes, ni los logros de las dinastías almorávides, almohades y merinidas. Nos vamos a ceñir a una época más reciente, a nuestro siglo. Como dice Gabriel Camps "interroguemos no a los cementerios sino a la época contemporánea".

Fueron las tribus imazighen las que se opusieron rotunda y violentamente a la expansión colonial de Europa. Desde la conquista de Argel en 1830 por las tropas francesas hasta 1934, tras la sumisión del último bastión de Siba; el Magreb fue durante todo un siglo de "pacificación europea", teatro de numerosas batallas. La Kabilia de Argelia fue la última región en someterse en 1857 volviendo a sublevarse con Mokraní en 1871. En Libia, el imperialismo italiano se enfrentaba contra las armas de los bereberes ibaditas dirigidos por un targuí, Soleimán el Baronni. En Marruecos, tropas coloniales luchaban contra la guerra santa del Hiba y de su padre Ma el Ainine en el Sur para someter a sus tribus nómadas y montañosas transhumantes. Al principio de los años veinte Moha ou Hammou organizaba sus tribus zayans. La "pacificación" francesa también fue dura en la "mancha de Taza" combatiendo con las tribus disidentes de Branés Tsoul, Rhiaba y Ait Ourain. La última resistencia fue llevada por las tribus de Aït Atta en las montañas de Yebel Sarho en las batallas de Bou Gafer en 1933. En el Norte de Marruecos destacamos la guerra santa del Sherife Amezian dirigiendo la sublevación de las tribus Guelayas y de Ait Sidel contra la penetración española en la primera década del siglo $\mathrm{XX}$.

La insurrección rifeña bajo el liderazgo de Mohamed Ibn Abdelkrim merece una atención peculiar. Esta tuvo palpables consecuencias a corto y largo plazo. Las profundas consecuencias históricas nos obligan a decir algo de esta espléndida y cruel experiencia. Quién se figuraba en el año crucial de 1921, que una simple resistencia, quizás animada por una cierta desilusión del Protectorado español, se convirtiera, tras derrotar a las tropas avanzadas del general Silvestre, en la batalla de Annual, que serfa incluso un modelo de las guerras de liberación del Tercer Mundo. Las tribus de Aït-Urriagel, Aitt-Tenssaman, Aït-Tuzin y Bocoya tras las sucesivas batallas de Ben Tieb, de Yebel Amuit, de Seluán 
y de Nador, ignoraban ser el motor directo del golpe de estado del General Primo de Rivera en 1923. Este último fue aclamado por su política de abandonar el Rif. Pero para la Francia de Lyautey, la revolución rifeña representaba ya un evidente peligro para su obra de "pacificación". La "marea rifeña" de 1925 condujo a movilizar todo el arsenal militar y a coordinar las operaciones militares de las dos potencias coloniales para aplastar la insurrección de los imazighen libres y obligar a rendirse a "ese jefe político que había extendido sus ambiciones hasta una idea nacional y aún más, al juego internacional", según el juicio de Jacques Berque.

El 27 de mayo de 1926 se desvanece el sueño de liberación del Rif, primera etapa de real-politik hacia la liberación de Marruecos. Y, más tarde, ya en el exilio, Abdelkrim el Jatabi presidirfa el Comité de Liberación del Magreb, en el Cairo.

Las cenizas y crueldades de la guerra del Rif se desplazaron desgraciadamente después a la Península Ibérica, donde los vencedores, el ejército de Africa, y los vencidos, las tribus rifeñas, en una "paradojica compenetración" según palabras de Víctor Morales Lezcano, combatieron juntos para aplastar la rebelión de los mineros y metalúrgicos asturianos, en octubre de 1934, poniendo en peligro la Segunda República Española. Esta última, negando la reivindicación autonómica del Norte de Marruecos (1936), no pudo sobrevivir al pronunciamiento militar de Melilla (17 de julio de 1936) que acabo aplastando al Frente Popular armado. La guerra civil en España fue una de las más trágicas y fratricidas. Ni la sublevación de la marina, ni el juramento del ejército del Aire a la Segunda República Española impidieron el traslado de las tropas "rifeñas y del Tercio" al suelo ibérico. Como cita María Rosa de Madariaga en el coloquio de París sobre Abdelkrim: "El triunfo del ejército de Francisco Franco se debe en gran medida al reclutamiento de los miles de combatientes rifeños y por la falta total del conocimiento del problema colonial de los socialistas españoles: "...la lucha de la liberación nacional del pueblo marroquí estuvo estrechamente ligada a la lucha revolucionaria del proletariado español".

No es una pura coincidencia el final de la guerra del Rif con la gestación del nacionalismo magrebí. La lucha polftica tomaba el relevo por una conciencia política de los grandes temores de los movimientos nacionales del Magreb como los liderados por Abdeljalak Torres, Allal El Fassi y el prestigioso argelino Messali Hadj, fundador de L'Etoile Nord Africaine. 
El famoso "Dahir Bereber" elaborado en mayo de 1930 no pudo borrar los esfuerzos de los imazighen condenándolos a callar a causa de una falsa colaboración con el colono francés. Un exagerado mito de los historiadores que no tuvo contundentes aplicaciones en la realidad tamazight. Las regiones bereberes siguieron siendo las más desfavorecidas. El desencanto social se fulmino en 1954 con la toma, una vez más, de las armas con el fin de liberar para siempre al gran Magreb. Después de la matanza de "Toussaint", Kabilia se alzó proporcionando grandes jefes politicos-militares del FLN y ALN argelinos, como Abane, Amirouche, Krim Belkasen y Hocine Ait Ahmed "sin relación con el peso demográfico". En el Rif Central y en el Medio Atlas las tribus siguieron el mismo camino histórico obligando a la Residencia de Rabat a precipitarse a dar una independencia formal para Marruecos y Túnez. Según Hart: "los seiscientos o setecientos guerrilleros del ALN quienes maniobraron en "el triángulo de la muerte" entre Aknoul, Boured y TiziOussli pertenecían a las tribus de Gzenaïa, Ben Yahya, Mernissi y BeniSnassen.

Con esta visión muy resumida de los últimos hechos historicos en el Magreb y España, los imazighen de Argelia siguen tomando como es propio de sus tradiciones un papel activo y trascendental en la historia contemporánea del Mediterráneo occidental.

\section{La sociedad tamazight y su evolución socioeconómica}

Según los escritos de Robert Montagne, a finales del siglo XIX y comienzos del XX, el Magreb estuvo dividido en dos espacios: bled el Majzen bajo la autoridad central del sultanato, que reinaba sobre los centros urbanos; y bled siba, formado por las tribus disidentes del mundo rural. Se fingía en este extenso territorio rural un dominio del estado del desorden y de la anarquía social donde el colonialismo francés justificaba su mascarada política de "pacificación". Este sociólogo colonial se quedo sorprendido por la oculta organización social de estas coherentes tribus bereberes. Observó que estas organizaciones sociales eran el fundamental pilar de la supervivencia de la Berbería a través de los siglos, resistiendo a diversas penetraciones e imperios. Afirmaba que la sociedad bereber "oscilaba entre repúblicas o mejor dicho autonomías tribales democráticas, oligarquías y tiranfas efímeras". 
Por lo que respecta a la oposición al poder central, nos relata Ahmed Akouaou que "los bereberes sólo pretendieron verdaderamente una legitimidad defensiva (legitimidad histórica) un reconocimiento jamás explícitamente formulado. Son nada más que conflictos entre dos poderes políticos efectivos que no buscaron en la realidad nada más que ignorarse mutuamente. Es por esta razón fundamental que, para describir esta realidad, para ella nueva, la ciencia colonial prestó a la ideología central el concepto de siba (anarquia, desorden)".

A fin de cuentas, siguiendo a Gabriel Camps, el mundo bereber conoció una diversidad y heterogeneidad al respecto de las organizaciones políticas y sociales. Por ejemplo en el Mzab, los bereberes ibaditas, muy arraigados en la fe musulmana se organizaban según djemas teocráticas donde el poder estaba concentrado en manos de un consejo de clérigos: "los azzabs y los tolbas". Sus ciudades eran verdaderas fortalezas religiosas.

La sociedad targuí era de tipo aristocrática, muy jerarquizada, que conservaba los rasgos de la organización primitiva. El linaje es matrilineal, como los Imouhar o los Kel Rela, descendientes de Tin Hinan. Amenokal es descendiente de esta última y ocupa el poder como monarca feudal. Y lo curioso es que esta sociedad aún conserva el esclavismo.

Lo que era frecuente y repetitivo era la organización social de tipo segmentaria estudiada minuciosamente por profesores como David M. Hart, David Seddon y Ernest Gellner.

Según Hart, tanto los Ait Atta de Yebel Sarho, como los Ait Uariaguel del Rif Central, estaban divididos en cinco segmentos de linajes, cuyo nombre es el de khoms. Asf́ los Ait Uariaguel estaban divididos en Khams Khmas (cinco quintos), de casi igual grandeza (Ait Abdellah, Ait Bou Ayyach, Ait Yousef W'-Ari, Ait Hadhifa, e Imrabdhen). Cada estructura estaba bajo el poder de un jefe temporal que llevaba el nombre de Amghar. Había diferentes niveles de agrupamiento social: una federación de tres o cuatro caseríos formaban la aldea, que, a su vez, agrupándose con otras aldeas formaba el cantón. Los cantones, a su vez, formaban la tribu. Así se podía organizar una confederación de tribus en el nivel más importante de la organización social. La familia tamazight era en este aspecto, patriarcal y agnaticia.

Paul Pascon describió la tribu como "una asociación política fundada sobre factores económicos-geográficos, relación entre el hombre y la tierra, de la energía humana y la riqueza ecológica en un nivel 
tecnológico determinado". Los poderes municipal, judicial y ejecutivo pertenecían a una asamblea del pueblo, donde los hombres en estado de llevar las armas podían tomar la palabra. Pero en la práctica eran los nobles o los viejos los que tomaban las decisiones de la Djemaa.

Había instituciones de alianza (leff o soff) oligarquias de tribus que jugaron un papel primordial en el funcionamiento de la vida social de los bereberes.

La pacificación colonial consistió, a fin de cuentas, en demoler estos pilares de la organización social jamás conocida en la historia del pueblo amazigh. Causando por consiguiente un verdadero estado de caos. y desorden social que solamente la emigración masiva hacia los centros urbanizados acabaron por tranquilizar. Una vez destruidas las bases de la economía tradicional, los bereberes sufrieron el éxodo rural y una emigración transmediterránea. Como dice Khatibi: "desposerdas las tribus de su fuerza militar, el Estado creó las condiciones de una apropiación del espacio y la economia". Las fuerzas físicas de este pueblo se revelaron de gran utilidad a las industrias europeas. Los que se quedaron formaron parte integrante de la clase obrera magrebi, convirtiéndose en asalariados. Si en las grandes ciudades europeas fueron marginados $\mathrm{e}$ introducidos en insalubres guetos, condenados a múltiples exclusiones, atormentados por la miseria afectiva y sexual, víctimas de xenofobias y racismos, los inmigrantes kabileños, susis y rifeños representan en la actualidad una importante fuente de ingresos, en divisas para sus países respectivos.

\section{La cuestión sensible: la lengua tamazight}

Quizás es la cuestión más sensible de la identidad bereber, el factor más discriminatorio y polémico. Posiblemente la identificación de los imazighen se basa más en el reconocimiento de su lengua que vive una fase histórica crítica: desaparecer o perdurar, ese es el problema. De todas formas, toda lengua es soporte de una civilización. Como dice Wemer Vycichl: "un vocabulario bereber se presenta como un libro de historia donde aparece todo el pasado del pueblo; sus instituciones, sus creencias, los vestigios de la mitología lejana, aportaciones de civilizaciones extranjeras...". Así condenar una lengua es cometer un crimen a la civilización, en expresión de Roland Barthes. Si la lengua tamazight 
actual encierra en su seno palabras latinas y árabes, este es reflejo de la estrecha relación histórico-comercial y la rica convivencia de los bereberes con el mundo romano y musulmán.

En la actualidad se plantean muchas preguntas en su entorno, no es casual el florecimiento de licenciaturas y tesis doctorales universitarias que abundan en las facultades universitarias de Francia, Marruecos, Argelia y otros países. Una broma de A. Khatitbi dice: "nosotros los magrebres hemos estado aprendiendo durante siglos la lengua árabe, más de un siglo aprendiendo el francés y desde tiempos inmemoriales no hemos sabido escribir el bereber".

Como es sabido, la lengua castellana antes de ser lengua era un dialecto derivado del latín, y antes de pasar a la escritura, era de tradición oral. Lo mismo ocurre con la lengua catalana y el euskera. Pues bien, la lengua bereber primitiva que se hablaba en todo el Magreb comenz 6 a decrecer lenta y progresivamente desde la Edad Media. El proceso de arabización que surgió con la llegada de las tribus árabes hilalianas se reforzaba por una triple acción: la conversión unánime de los imazighen al islam extendiéndose hasta Andalucía por las grandes dinastras bereberes, la consiguiente valorización de la lengua árabe como lengua sagrada del Corán y el establecimiento de un nuevo poder urbano, que defendía la propagación de la lengua escrita. Los protectorados europeos facilitaron a su vez la arabización que se aceleró de una manera progresiva tras la independencia de los estados del Magreb. Estos últimos, ignorando la presencia lingüística tamazight embistieron con todas las instituciones contra ella: a través de la burocracia administrativa, los partidos políticos, y los nuevos medios de comunicación. Esta visión autoritaria de la unidad arabo-islámica convirtió esta cuestión en un tabú incomprensible y paradojico. Esta rotunda amenaza de erosión cultural ha conducido últimamente a los bereberes hacia una toma de conciencia efectiva. Sin contravenir la unidad de los Estados, ni la necesidad de aprender el árabe, las reivindicaciones irreductibles se desarrollan "de una forma unánime en lo cultural, en la identidad histórica, lingüística y escolar". Se planté en Argelia la polémica con una cierta virulencia en abril de 1980, con la represión de las manifestaciones de Tizi-Ouzou, emprendidas al prohibir una conferencia de Mouloud Mammeri, el precursor de la lucha bereber, como se le atribuye. Lo que también defendió el Frente de las Fuerzas Socialistas, de Hocine Ait Ahmed, al incluir como objetivo primordial de su programa político el reconocimiento de 
la tamazight como segunda lengua oficial de Argelia. El partido de Said Saidi siguió la misma trayectoria.

Igualmente, la apertura democrática en Argelia se debe a las organizaciones de derechos humanos donde los kabilianos jugaron un papel decisivo. En 1991 se ha reconocido la lengua tamazight en la Universidad de Tizi-Ouzou donde fue creado un departamento al respecto. Ultimamente Marruecos es también terreno de un florecimiento cultural, destacando el importante trabajo de transcribir la lengua oral de Souss a la escritura.

\section{Conclusión}

Melilla que está compuesta de una comunidad tamazight bastante numerosa, tiene la obligación democrática de tomar en consideración a esta identidad que fue, es y será siempre parte integrante de su patrimonio cultural. El futuro de Melilla se presenta carente de este fabuloso bagaje cultural, vital para una verdadera comprension mutua y para una duradera convivencia entre sus diferentes comunidades. La lengua tamazight es ya una realidad social de la vida cotidiana melillense. A este respecto, Melilla debe proporcionar centros de estudios e investigación para divulgar dicha cultura.

Si las dos culturas pudieron sobrevivir juntas en Andalucía, en la Edad Media, en Melilla se presenta ahora otra vez la oportunidad histórica que debe aceptar el reto de existir armoniosamente entre las diferentes culturas. Como dice el sociolingüista Salem Chaker: "Todos los magrebies (y también los melillenses) tienen mucho que ganar asumiendo y enriqueciéndose de la cultura tamazight, aceptando su complejidad y diversidad".

\section{BIBLIOGRAFIA}

Abd el -Krim et la république du Rif (Actes du colloque international d'études historiques et sociologiques, 18-20 janvier, 1973). Paris, 1976.

1986.

Actualité de Robert Montagne, Regards sur le Maroc. Cheam, 1981.

Amazigh, revista marroqui de historia y de civilización. Rabat, “Aproximación a las Culturas Mediterráneas del Norte de 
Rachid Ahmed Raha

Africa". En: Publicaciones de la Escuela Universitaria del Profesorado de E.G.B. Melilla, 1983. 1978. ( $2^{s}$ ed.).

BERQUE, Jacques. Structures sociales de Haut-Atlas. París,

"Berberes, une identitè en construction". En: Revue de l'Occident Musulman et de la Méditerrannée. Aix-en Provence, 1987.

CAMPS, Gabriel. Les bérbères, mémoire et identité. Paris, 1987 ( $2^{s}$ ed.).

CHAKER, Salem. Berbéres, aujourd'hui. Paris, 1990

DESCOLA, Jean. Ô Espagne. París, 1976.

Provence, 1984.

Encyclopédie Berbère. (Dirigida por G. Camps). Aix-en-

España y el Norte de Africa, bases históricas de una relación fundamental. (Actas del primer Congreso Hispano-Africano de las culturas mediterráneas). Melilla, 1984.

Etudes et documents Berberes. París, 1986.

GELLNER, E. and MICAUD, C. Arabs and Berbers: From tribe to Nation in North Africa. London, 1973.

GUERIN, Daniel. Quand l'Algerie s'insurgeait (1954-1962). 1979.

HART, David M. The Aith Waryaghar of the Moroccan Rif. An Ethnography and History. Arizona, 1976.

HUGH, Thomas. La guerra civil de España. París, 1962.

JAMOUS, Raymond. Honneur et Baraka. Paris, 1981.

KHATIBI, Abdelkabir. Maghreb pluriel. Paris, 1983.

La Culture Populaire: spécifités locales et dimensión nationale. (Asociación de la Universidad de Verano de Agadir). Okad, 1990.

Las Comunidades europeas y el Norte de Africa. Jaén, 1989.

MADARIAGA, $\mathrm{M}^{\mathrm{a}}$. Rosa de. L'Espagne et le Rif: penetration coloniale et résistances locales (1909-1926). (Thèse doctorat sous le direction de Pierre Vilar). Paris, 1987.

MARTÍN, Miguel. El colonialismo español en Marruecos (1860-1956). París, 1973.

M'BAREK, Zaki. Resistance et Armée de liberation. Portée polítique, liquidation 1953-1958. Tánger, 1987.

MONTAGNE, Robert. Les Berberes et le Makhzen dans le Sud du Maroc. Casablanca, 1989 (2 . ed.). 
MORALES LEZCANO, Víctor. España y el Norte de Africa: el protectorado en Marruecos (1912-66). Madrid, 1981.

SERVIER, Jean. Les Berbères. Paris, 1990.

Tafsut: Etudes et débat. (Dirigida por Salem Chaker). TiziOuzou/Aix-en-Provence, 1987.

WOOLMAN, David S. Abdelkrim y la rebelión del Rif. Barcelona, 1968. 